\title{
AKTIFITASPEMBINAAN MASYARAKAT DESA HUTAN (PMDH) OLEH IUPHHK PT. MANCARAYA AGRO MANDIRI KABUPATEN SORONG
}

\author{
IRNAWATI \\ irnawatif@gmail.com \\ Dosen Kehutanan Universitas Muhammadiyah Sorong (UMS)
}

\begin{abstract}
Abstrak
Tujuan dari penelitian ini adalah mengetahui kegiatan pembinaan dan persepsi masyarkat terhadap upaya kegiatan pengembangan pembinaan masyarakat desa hutan oleh pt. mancaraya agro mandiri distrik moraid kabupaten sorong.

Penelitian ini menggunakan metode survey dengan teknik observasi dan wawancara. Penentuan sampel partisispasi masyarakat terhadap desa binaan IUPHHK PT. Mancaraya Agro Mandiri Kabupaten Sorong dimana kegiatan Pembinaan Masyarakat Desa Hutan (PMDH) dilakukan dengan menggunakan metode purposive sampling (sampel bertujuan),

Hasil penelitian adalah kegiatan pembinaan terhadap masyarakat kampung di areal IUPHHK PT. Mancaraya Agro Mandiri sesungguhnya sudah dilakukan sejak tahun 2005-2015 selama 10 tahun berjalan. Dan sudah memiliki 9 Desa/kampung binaanya itu, namun dalam penelitian ini peneliti mengambil 2 kampung sampel penelitian yang dijadikan acuan kegiatan-kegiatan PMDH oleh IUPHHK PT. Mancara Agro Mandiri yaitu Kampung Selewok dan Kampung Saengkeduk dengan alasan bahwa kedua kampung tersebut sangat dekat dengan base camp perusahan dalam aktifitas produksi hutan kayu.Persepsi masyarakat responden pembinaan masyarakat kampung hutan PTMancaraya Agro Mandiri dalam segi manfaat terdapat (80\%) menyatakan bermanfaat Adapun saran-saran dalam Penelitian ini antara lain: Mengingat Kegiatan PMDH sudah dilakukan selama 10 tahun berjalan dan memiliki 9 kampung binaan maka saran kami perlu ada penelitian lanjutan mengenai beberapa kampung yang belum terjangkau oleh penelitian.Perlu adanya upaya peningkatan kondisi sosial dan ekonomi masyarakat sekitar sehingga akses untuk memanfaatkan sumber daya alam disekitar kawasan secara berlebihan dapat di kurangi dengan melihat tingginya manfaat kegiatan PMDH oleh PT. Mancaraya Agro Mandiri sehingga mengambil hasil hutan semakin berkurang. Perlu diupayakan adanya bentuk penyuluhan terpadu yang melibatkan pemerintah daerah untuk memberikan pemahaman yang tepat mengenai fungsi dan peranan dari hutan produksi yang dilakukan oleh PT. Mancaraya Agro Mandiri, efek kerusakan, pemanfaatan yang berlebihan dan penebangan liar pada masyarakat sekitar dalam kawasan hutan produksi PT. Mancaraya Agro Mandiri.
\end{abstract}

Kata Kunci :Aktifitas pembinaan masyarakat desa hutan, hutan produksi

\section{PENDAHULUAN}

Latar belakang

Kebijakan pemerintah memalui

Keputusan Menteri Kehutanan

No.523/Kpts-II/1997, telah mewajibkan kepada pemegang HPH untuk lebih peduli terhadap upaya - upaya pembinaan masyarakat tradisional yang berada didalam dan disekitar areal kerja $\mathrm{HPH}$ dalam rangka meningkatkan 
kesejateraan, kebijaksanaan ini dikenal dengan Pembinaan Masyarakat Desa Hutan (PMDH).

Kebijaksanaan PMDH oleh PT Mancaraya Agro Mandiri adalah kegiatan yang merupakan upaya sektor swasta kehutanan terutama para pemegang IUPHHK-HA untuk mendistribusikan sebagian keuntungan dari kegiatan pengusahaan hutan untuk pengembangan masyarakat local /tradisonal di Distrik Moraid areal konsesi PT. Mancaraya Agro Mandiri. Kegiatan Pembinaan Masyarakat Desa Hutan (PMDH) adalah salah satu kewajiban PT. Mancaraya Agro Mandiri dalam membantu meningkatkan kesejateraan masyarakat didalam dan disekitar hutan Distrik Moraid dimana perusahan tersebut beroperasi.

Oleh karena itu untuk dapat melakukan kebijakan pemerintah dalam hal perubahan pembangunan dan perubahan kehidupan sosial memerlukan waktu dan proses yang lama, dengan demikian kegiatan pembangunan masyarakat didalam dan disekitar hutan harus diarahkan pada proses evolusi dari pada revolusi seperti yang dilakukan IUPHHK-HA saat ini. Kegiatan PMDH harus pula menjadikan peran masyarakat didalam dan disekitar hutan sebagai sumberdaya potensial, tidak lagi sebagai sumber ancaman. Masyarakat di kampungkampung Distrik Moraiddidalam dan disekitar hutan harus diakui sebagai sumberdaya yang penting dalam rangka mendukung pencapaian manajemen hutan lestari, sehingga secara tidak langsung turut mendukung upaya pencapaian tujuan pembangunan nasional untuk menciptakan masyarakat Indonesia yang sejatera.

Guna mewujudkan upaya tersebut, Pembinaan sumberdaya manusia atau aktor yang terlibat pada setiap tahap kegiatan mutlak diperlukan. Aktor - aktor tersebut yaitu pemegang IUPHHK-HA dalam hal ini adalah PT. Mancaraya Agro Mandiri, masyarakat binaan Kampung Distrik Moraid, dan Instansi terkait di Kampung Distrik Moraid Kabupaten Sorong, tulisan ini menjelaskan tentang kegiatan Pembinaan Masyarakat Desa Hutan di IUPHHK PT. Mancaraya Agro Mandiri serta persepsi masyarakat terhadap upaya kegiatan Pembinaan Masyarakat sesuai dengan karakteristik masyarakat adat setempat.

\section{Rumusan Masalah}

Berdasarkan uraian latar belakang diatas, maka yang menjadi rumusan masalah dalam penelitian ini adalah :

1. Bagaimana Kegiatan Pembinaan Masyarakat Desa Hutan di PT. Mancaraya Agro Mandiri Distrik Moraid Kabupaten Sorong

2. Bagaimana Persepsi masyarakat terhadap upaya Kegiatan Pembinaan Masyarakat Desa Hutan di PT. Mancaraaya Agro Mandiri Distrik Moraid Kabupaten Sorong

\section{Tujuan Penelitian}

Berdasarkan rumusan masalah diatas, maka ditetapkan tujuan daripenelitian ini, yang dapat diuraikan sebagai berikut:

1. Mengetahui Kegiatan Pembinaan Masyarakat Desa Hutan oleh PT. Mancaraya Agro Mandiri Distrik Moraid Kabupaten Sorong

2. Mengetahui Persepsi masyarkat terhadap upaya Kegiatan Pengembangan Pembinaan Masyarakat Desa Hutan oleh PT. Mancaraya Agro Mandiri Distrik Moraid Kabupaten Sorong

\section{METODE PENELITIAN}

Penelitian ini dilaksanakan di PT.Mancaraya Agro Mandiri 
Kabupaten Sorong Penelitian ini dilaksanakan selama 2 bulan, yakni pada bulan Desember-Januari 2015. Tempat penelitian di IUPHHK PT.Mancaraya Agro Mandiri Kabupaten Sorongyang terdiri dari 2Kampung binaan yang berada di dalam kawasan tersebut, yaitu Kampung Selewok yang merupakan pusat kegiatan (base camp) PT. Mancaraya Agro Mandiri Distrik Moraid Kabupaten Sorong, Kampung Binaan Sengkedukyang masih berada di dalam areal namun jaraknya tidak cukup jauh dari lokasi camp PT. Mancaraya Agro Mandiri Kabupaten Sorong

Metode yang di pakai dalam penelitian ini adalah metode survey dengan teknik observasi dan wawancara. Penentuan sampel partisispasi masyarakat terhadap desa binaan IUPHHK PT. Mancaraya Agro Mandiri Kabupaten Sorong dimana kegiatan Pembinaan Masyarakat Desa Hutan (PMDH) dilakukan dengan menggunakan metode purposive sampling(sampel bertujuan),

Teknik penelitian yang akan digunakan dalam penelitian ini adalah:

1. Teknik Wawancara

Data dikumpulkan dengan melakukan Tanya jawab secara langsung terhadap responden, pejabat setempat, pemimpin formal maupun informal desa serta dari pihak pelaksana PMDH yang berasal dari perusahaan. Wawancara dilakukan dengan menggunakan daftar pertanyaan/kuesioner terstruktur dan tidak terstruktur mengenai hal-hal yang berhubungan dengan penelitian.

2. Pengumpulan data-data sekunder dari pihak PT. Mancaraya Agro Mandiri dan dari kepala kampung Desa Selewok dan Desa sengkeduk. Yang menjadi dasar variable penelitian ini adalah sebagai berikut:

1. Kegiatan Pembinaan Masyarakat Desa Hutan di IUPHHK PT. Mancaraya Agro Mandiri Distrik Moraid Kabupaten Sorong

2. Persepsi MasyarakatPembinaan Masyarakat Desa Hutan di IUPHHK PT. Mancaraya Agro Mandiri Distrik Moraid Kabupaten Sorong

Data dianalisis secara diskriptif dan disajikan dalam bentuk tabel dan gambar/foto

\section{HASIL DAN PEMBAHASAN}

\section{A. Deskripsi Lokasi}

1. Lokasi Umum Penelitian

PT. Mancaraya Agro Mandiri

selaku Pemegang Izin Usaha Pemanfaatan Hasil Hutan Kayu (IUPHHK) didirikan berdasarkan Akte Notaris Darby, SH No. 12 tanggal 8 Juni 1999 dan Pengesahan Menteri Kehakiman No. C- 19287. HT.01.HT.99 tanggal 29 November 1999, kemudian diubah dengan Akte Notaris Darby, SH No. 15 tanggal 2 Mei 2001 dan Pengesahannya oleh Menteri Kehakiman No. C- 08246. HT. 01. 04. TH. 2001, dan selanjutnya diubah dengan Akte Notaris Hetyani Hassan, SH, MKn. No. 55 tanggal 25 Mei 2010.

Berdasarkan Keputusan Bupati Sorong Nomor 105 Tahun 2001 tanggal 31 Oktober 2001 kepada PT. Mancaraya Agro Mandiri telah diberikan Izin Usaha Pemanfaatan Hasil Hutan Kayu (IUPHHK) pada hutan alam seluas $\pm 99.750 \mathrm{Ha}$ yang terletak di kelompok Hutan Sungai Sekowa - Sungai Warmanen, Sungai Mega- Sungai Warsamson dan Sungai Kladuk - Sungai Seni, Kabupaten 
Sorong untuk jangka waktu 35 (tiga puluh lima) tahun.

Berdasarkan Badan planologi Kehutanan sesuai Surat Nomor S.31/VII-Set/Rhs/2006 tanggal 13 Februari 2006, direkomendasikan areal tersebut menjadi Seluas + $97.820 \mathrm{Ha}$ yang terdiri dari:

a. Blok B Seluas $2.897 \mathrm{Ha}$,

b. Blok C1 Seluas $\pm 24.857 \mathrm{Ha}$

c. Blok C2 Seluas $\pm 21.602 \mathrm{Ha}$ dan

d. Blok D Seluas $\pm 48.464 \mathrm{Ha}$.

Selanjutnya Menteri Kehutanan dengan Surat Keputusan Nomor SK.55/Menhut-II/2006 tanggal 14 Maret 2006 memberikan pembaharuan Izin Usaha Pemanfaatan Hasil Hutan Kayu (IUPHHK) pada hutan alam kepada PT. Mancaraya Agro Mandiri atas areal Hutan Produksi Seluas \pm 97.820 Ha.

\section{Kondisi Biofisik}

Areal IUPHHK PT. Mancaraya Agro Mandiri terdiri dari beberapa blok, yaitu blok B, blok $\mathrm{C} 1$, blok C2, dan blok D. Adanya blok - blok tersebut disebabkan karena areal kerja ini sebagian besar berbatasan dengan hutan lindung, untuk lebih jelasnya, letak dan luas areal kerja IUPHHK PT. Mancaraya Agro Mandiri ini disajikan pada (Lampiran).

\section{Fungsi Hutan}

Berdasarkan Peta Penunjukan kawasan Hutan dan perairan Provinsi Irian Jaya Skala $1: 250.000$ (Lampiran SK Menhut No. 891/Kpts/II/1999 tanggal 14 Oktober 1999) fungsi kawasan hutan areal kerja IUPHHK PT. Mancaraya Agro Mandiri terdiri atas Hutan Produksi Terbatas (HPT) Seluas $\pm 6.353 \mathrm{Ha}$, Hutan Produksi Tetap (HP) Seluas \pm 48.263 Ha dan Hutan Produksi yang dapat Dikonversi (HPK) Seluas \pm 43.204 Ha.

\section{Geologi dan Tanah}

Jenis tanah di areal kerja IUPHHK PT. Mancaraya Agro Mandiri diperoleh dari Peta Tanah Provinsi Irian Jaya, skala $1: 500.000$, pusat penelitian Tanah dan Agroklimat, Badan Penelitian dan Pengembangan Pertanian, tahun 1983. Sebagian besar jenis jenis tanah yang ada di wilayah tersebut adalah jenis komplek Podsolik Haplik dan Kambisol Distrik dan sebagian kecil Gleisol Distrik. Geologi

Formasi Geologi di areal kerja IUPHHK PT. Mancaraya Agro Mandiri diperoleh dari Peta Iktisar Geologi Provinsi Irian Jaya, skala 1 : 500.000 yang diterbitkan oleh pusat Penelitian dan Pengembangan Geologi Bandung. Formasi Geologi yang ada antara lain Formasi SPx, Tqa4, JKt Tmk, Qa dan Q1.

\section{Iklim, Suhu dan Hidrologi}

Kondisi Iklim di areal kerja IUPHHK PT. Mancaraya Agro Mandiri diperoleh dari data stasiun Meteorologi, Sorong. Menurut Klasifikasi Schmidt dan Ferguson, areal kerja IUPHHK termasuk tipe iklim A dengan nilai $\mathrm{Q}=0 \%$. Berdasarkan hasil perhitungan, terlihat hujan terjadi setiap bulan, selanjutnya data curah hujan secara lengkap dapat disajikan pada (Lampiran).

Areal PT. Mancaraya Agro Mandiri Blok B terletak di DAS Mega, Blok C1 dan Blok C2 berada di DAS Warsamson. Lokasi Blok D beradah terpisah di sebelah selatan dan termasuk dalam DAS Seni, SubDAS Kladuk, Sub-DAS Susian dan Sub-DAS Seni. Secara rinci kondisi sungai terdapat di areal kerja IUPHHK PT. Mancaraya Agro Mandiri

Areal kerja IUPHHK PT. Mancaraya Agro Mandiri merupakan daerah hulu sungai yang memiliki banyak aliran sungai-sungai kecil, 
dangkal, sempit dan berkelok-kelok dengan dasar sungai batu kerikil, dan pasir. Pola drainase sungai-sungai tersebut adalah dentritik berbentuk daun dengan satu sungai utama. Aliran sungai masih kintinyu, namun mengalami penurunan debit aliran saat musim kemarau, dan saat musim hujan terjadi peningkatan yang dapat mengakibatkan banjir dan erosi. Pemanfaatan sungai untuk sumber air minum dan tidak digunakan untuk keperluan transportasi.

\section{Flora dan Fauna}

Informasi tentang Flora yang khas dikumpulakan dengan cara mencatat jenis Flora yang dijumpai sepanjang jalur ukur survey termasuk didalamnya adalah mencatat data mengenai tumbuhan bawah, jenisjenis hasil hutan non kayu, getah, lebah madu, dan lain-lain. Adapun pencatan jenis Fauna di lapangan apa bila :

a. Ditemukan individu tertentu dalam wujud nyata yang terlihat pada saat diadakannya survey (pertemuan langsung).

b. Ditemukannya kotoran, jejak kaki, bekas gigitan yang dapat diidentifikasi, suarannya dan lain-lain.

c. Dilakukan wawancara dengan penduduk atau karyawan yang ada disekitar areal kerja yang disurvey.

a. Flora

Tipe hutan di areal kerja IUPHHK PT. Mancaraya Agro Mandiri adalah hutan hujan tropika dataran rendah. Jenis tumbuhan yang dapat di areal kerja IUPHHK ini disajikan pada (Lampiran)

Terdapat pula dua spesies khusus yang dilindungi, yaitu kayu hitam atau beneare (Diasphyros sp) dan binuang atau sering dibedakan menjadi binuang laki (Duabanga mulucana), namun demikian menurut SK Menteri pertanian No.54/Kpts/Um/2/1972, tentang pohon-pohon didalam kawasan Hutan yang dilindungi, jenis kayu hitam termasuk dilindungi terbatas dan boleh ditebang jika telah mencapai diameter $(\mathrm{dbh})$ lebih dari $60 \mathrm{~cm}$. Jenis binuang laki sering dimanfaatkan masyarakat setempat untuk bahan bangunan dan embuatan kapal. Atas insiatif masyarakat, jenis ini akan dilindungi keberadaannya dengan status perlindungan mutlak.

Pohon beringin (Ficus sp) termasuk dilindungi karena pertumbuhannya yang selalu lebat. Secara ekologi merupakan habitat bagi beberapa jenis satwa liar mulai dari strata atas (kanopi), strata tengah (percabangan dan ranting) dan strata bawah (permukaan tanah).

b. Fauna

Pengamatan jenis-jenis fauna yang terdapat di areal kerja IUPHHK PT. Mancaraya Agro Mandiri dalam tiga kelas yaitu kelas aves, mamalia dan reptilian. Data ini peroleh dengan survey lapangan, informasi masyarakat dan pegawai IUPHHK, temuan jejak (faces,tapak, bagian tubuh yang tertinggal) serta perjumpaan langsung pada umumnya kelangsungan hidup spesies satwa liar akan terjadi apabila terpenuhi kebutuhan hidup minimalnya, yang antara lain terdiri atas kecukupan ketersediaan ruang untuk berlindung, bermain, beristirahat maupun pergerakan. Ketersediaan pakan aktual maupun potensial bagi berbagai spesies satwa liar ditentukan oleh faktor-faktor : jumlah jenis-jenis tumbuhan pakan, serta luasan areal yang menjamin kelestarian produksi pakan. Kelimpahan suatu satwa liar tidak mudah untuk dihitung kecuali 
dengan penandaan sensus dengan waktu pengamatan yang relativ panjang. Hal ini disebabkan satwa liar dapat bergerak cepat dan sulit dikumpulkan. Penyebaran satwa menggambarkan tingkat kemampuan survival satwa dengan berpindah tempat dan berkembang biak pada suatu wilayah hidupnya. Diantara jenis-jenis status satwa selengkapnya disajikan dalam (Lampiran).

\section{Kondisi Sosial Ekonomi, Budaya dan Adat Istiadat}

\section{SosialEkonomi dan Adat}

\section{Istiadat}

Pada areal kerja IUPHHK PT. Mancaraya Agro Mandiri banyak terdapat adanya klaim land tenure "tanah/marga" oleh masyarakat desa sekitar/dalam kawasan hutan. Klaim land tenure tersebut berpengaruh pada sistem penguasaan lahan masyarakat, yaitu menganut pola pemilikan lahan atas nama keluarga (Marga).

Sistem penguasaan lahan masyarakat didalam/sekitar areal kerja IUPHHK PT. Mancaraya Agro Mandiri, secara garis besar yaitu :

1. Kepemilikan lahan oleh etnis asli (Marga-marga Ulim, Seni, Yeblo, Yekwan, Yenjaw, Malak, Gifelem, Safisa, Paa, Do, Lagu, Salamala, Klami, Klouw, Malagi, Ulimen, Maas, Karon, Klesi, Sekamuk, Meskidi dan Mielem). Sebagian besar anggota masyarakat tersebut hidup sebagai peramu (memungut hasil hutan dan berburu). Luas lahan marga tersebut berkisar antara puluhan sampai ribuan hektar, sedangkan luas lahan yang digarap sebagai ladang/kebun oleh setiap anggota keluarga berkisar antara 0,1-1,0 $\mathrm{Ha} / \mathrm{KK}$.

2. Kepemilikan lahan oleh etnis pendatang dari Buton, Bugis dan
Maluku Utara yang sudah puluhan tahun bahkan ratusan tahun bermukin didesa-desa tepi pantai. Secara umum masyarakat desa tersebut memilih pola nafkah ganda, yaitu sebagai peladang dan nelayan. Luas ladang/kebun yang digarap masyarakat ini berkisar antara 1,25-1,5 Ha/KK. Sumber kepemilikan lahan berasal dari pewaris jual beli dan membuka hutan.

3. Dalam kehidupan sehari-hari masyarakat sekitar areal selalu menggunakan pranata sosial, yaitu suatu tahanan atau yang dipegang teguh masyarakat untuk menjaga kebutuhan dan kerukunan masyarakat. Sistem pranata sosial tersebut terdiri dari aspek-aspek :

a. Sistem Norma, yaitu aturanaturan yang mendasari adatistiadat dan hokum Informal masyarakat menganut sistem patrilineal, menghomati hasil keputusan adat dan batas wilayah marga, memberlakukan sanksi adat (kain timor, ternak dan uang), tidak membuang kotoran pada aliran sungai, dan sebagainya.

b. Kelakuan berpola, yaitu kebiasaan masyarakat sehari-hari meramu dan berburu, peladang dan nelayan.

c. Alat dan teknologi, yaitu : Kepemilikan alat-alat dan teknologi yang mencerminkan penguasaan sistem pengetahuan yang masih bersifat tradisional, misalnya parang, panah, tombak, jarring, jerat/perangkap, tifa dan alat-alat pesta/ritual adat.

d. Masyarakat pendukung yaitu : Kelembagaan masyarakat adat 
(Kepala marga, ondoafi/kepala suku, perangkat

Dusun/Desa/Kecamatan) sebagai pendukung ketiga aspek tersebut diatas.

\section{B. Deskripsi Identitas Responden}

a. Umur Responden

Responden adalah masyarakat yang berasal dari Desa binaan

Tabel1 : Responden Kelompok Jenis kelamin PMDH Oleh IUPHHK PT. Mancaraya Agro Mandiri

\begin{tabular}{llll} 
No Urut & Jenis kelamin & Jemlah Responden & Persentase \\
\hline 1. & Laki-laki & 39 & 65 \\
2. & Perempuan & 21 & 35 \\
\hline Jumlah & & 60 & 100 \\
\hline
\end{tabular}

Sumber : Hasil Olah data primer

Tabel : Responden Kelompok Umur PMDH Oleh PT. Mancaraya Agro Mandiri

\begin{tabular}{lccc}
\hline No Urut & Kelompok Umur & Jemlah Responden & Persentase \\
\hline 1. & $20-29$ & 2 & 3.33 \\
2. & $30-49$ & 9 & 15 \\
3 & $40-49$ & 19 & 31.67 \\
4 & $50-59$ & 11 & 20 \\
5 & $60-69$ & 13 & 21.67 \\
6 & $\geq 70$ & 6 & 10 \\
\hline Jumlah & & 60 & \\
\hline
\end{tabular}

Sumber : data primer setelah di olah

Tabel diatas menunjukan bahwa pada umumnya jumlah responden berada pada kelompok umur $40-49$ Tahun (31,67\%). Menurut Suyono (1991) usia Produktif adalah usia berada pada diatas 10 tahun dan kurang dari 50 tahun, sehingga responden pada umumnya berjenis kelamin laki-laki (65\%) dan masih produktif untuk bekerja. Hal ini sangat sesuai dengan kondisi dilapangan bahwa responden pada umumnya produktif untuk bekerja.
IUPHHK PT. Mancaraya Agro Mandiri Usia Responden yang diambil berkisar antara 22-71 Tahun. Distribusi responden menurut kelompok jenis kelamin dan kelompok umur dapat dilihat pada tabel1. berikut ini.

Tabel 2.Distribusi Responden Berdasarkan latar belakang tingkat Pendidikan

\begin{tabular}{llll} 
No Urut & Pendidikan & Jumlah Responden & Persentase \\
\hline 1. & Tidak Tamat SD & 2 & 3.33 \\
2. & SD & 9 & 15 \\
3 & SLTP & 19 & 31.67 \\
4 & SMA & 11 & 20 \\
5 & S1 & 13 & 21.67 \\
\hline
\end{tabular}




\begin{tabular}{lc}
\hline Jumlah 60 & 100 \\
\hline Sumber : data primer setelah di olah &
\end{tabular}

Tabel diatas dapat menunjukan bahwa tingkat pendidikan responden pada umunya $(36,67 \%)$ hanya tamat $\mathrm{SD}$, artinya tingkat pendidikan masyarakat di desa sampel masih termasuk rendah. Rendahnya tingkat pendidikan, pengetahuan dan keterampilan masyarakat didalam dan di sekitar hutan sangat di pengaruhi oleh tata nilai dan tradisi nenek moyangnya yang cendrung primitiv dan tradisional, sehingga kesadaran masyarakat akan pentingnya pendidikan masih rendah. Hal ini terlihat dari sebagian besar masyarakat hanya berpendidikan SD dan bahkan tidak tamat SD, sehingga sumberdaya yang sesungguhnya produktif yang dimilikinya belum bias dikelola dan dimanfaatkan secara optimal untuk meningkatkan kualitas hidupnya.

Rendahnya tingkat pendidikan masyarakat juga disebabkan oleh sarana pendidikan yang kurang memadai, hal ini terlihat dari minimnya sarana pendidikan di kedua desa tersebut. Desa Selewok satu SD, sedangkan Desa Saengkeduk juga hanya memiliki satu SD. Disamping keterbatasan sarana pendidikan tersebut, kesejateraan masyarakat desa binaan PT. Mancaraya Agro Mandiri bila dilihat dari tingkat pendapatan dan tingkat pendidikan yang masih rendah maka dapat disimpulkan bahwa tingkat kesejateraan masyarakat desa binaan PT. Mancaraya Agro Mandiri juga masih rendah.

c. Kepemilikan Lahan

Pada umumnya responden hidup dari mata pencaharian bertani sehingga kesejateraan hidup responden tergantung pada luas lahan kering yang dimilikinya. Luas kepemilikan lahan dapat dilihat pada Tabel dibawah ini.

Tabel 3, Distribusi Responden Berdasarkan Luas Kepemilikan Lahan

\begin{tabular}{llll} 
No Urut & Luas kepemilikan lahan $(\mathrm{Ha})$ & Jumlah Responden & Persentase \\
\hline 1. & $\leq 1$ & 2 & 3.33 \\
2. & $2-4$ & 9 & 15 \\
3 & $\geq 4$ & 19 & 31.67 \\
\hline Jumlah & & 60 & 100
\end{tabular}

Sumber : data primer setelah di olah

Dari Tabel diatas dapat dilihat bahwa pada umumnya responden memiliki luas lahan sekitar $2-4 \mathrm{Ha}$ (63,33\%), status kepemilikan lahan responden merupakan milik sendiri. Lahan-lahan milik responden tersebut pada umumnya berasal dari warisan,

namun ada juga yang berasal dari buka lahan sendiri/garap lahan sendiri serta ada yang berasal dari perusahan melalui Kegiatan Bina Desa Hutan (BDH), asal kepemilikan lahan responden dapat dilihat dalam Tabel dibawah ini . 
Tabel 4.Distribusi Responden Berdasarkan Asal Kepemilikan Lahan

\begin{tabular}{llll}
\hline No & Asal Kepemilikan lahan & Jumlah Responden & Persentase \\
\hline 1. & Warisan & 33 & 55.00 \\
2. & Buka Lahan Sendiri & 17 & 28.33 \\
3 & Kegiatan Bina Desa Hutan & 10 & 16.67 \\
\hline \multicolumn{2}{l}{ Jumlah } & 60 & 100
\end{tabular}

Sumber :data primer

Dari Tabel diatas dapat dilihat bahwa pada umumnya asal kepemilikan lahan responden berasal dari warisan $(55,00 \%)$. Kepemilikan lahan yang berasal dari warisan di Kampung Salewok dan kampung Saengkeduk adalah $55,00 \%$ sedangkan buka lahan sendiri tampa warisan dari marga atau hak ulayat dari masyarakat setempat sebanyak $28.33 \%$ dan masyarakat yang masuk dalam kegiatan bina desa hutan dengan dibantu oleh perusahaan PT. Mancaraya Agro mandiri sebanyak $16.67 \%$ d. Mata Pencaharian Responden.

Mata pencaharian responden dapat dikategorikan atas dua kelompok, yaitu dari usahatani dan non usahatani adalah berdagang, karyawan perusahaan, tukang kayu dan wiraswasta lainnya. Sumber pendapatan utama responden adalah usahatani. Distribusi mata Pencaharian/sumber pendapatan responden dapat dilihat pada Tabel dibawah ini

Tabel 5 dibawah ini Distribusi Responden Berdasarkan Mata Pencaharian

\begin{tabular}{|c|c|c|c|}
\hline No Urut & $\begin{array}{l}\text { Mata Pencaharian/sumber } \\
\text { pendapatan }\end{array}$ & $\begin{array}{l}\text { Jumlah } \\
\text { Responden }\end{array}$ & Persentase \\
\hline 1. & Usaha tani & 39 & 65 \\
\hline 2. & Non Usaha tani & 21 & 35 \\
\hline Jumlah & & 60 & 100 \\
\hline
\end{tabular}

Sumber : Hasil olah data

Tabel diatas menunjukan bahwa sumber pendapatan responden pada umumnya berasal dari usahatani (65\%). Usaha disektor pertanian pada umumnya juga dilakukan oleh

\section{Kegiatan Pembinaan Masyarakat Desa Hutan Oleh IUPHHK PT. Mancaraya Agro Mandiri}

\section{Tahap Perencanaan}

Berdasarkan sumber karyawan IUPHHK PT. Mancaraya Agro Mandiri bahwa (RKL) tahun dan (RKT) tahun sebagian sudah dilaksanakan dan di sahkan oleh pemerintah pusat sesuai dengan SK. Dirjen PH No. responden yang memiliki mata pencaharian disektor non unsahatani, namun sifatnya hanya sekedar sampingan yang berfungsi sebagai tambahan penghasilan rumah tangga.

288/Kpts/IV-PHH/1992 namun ada juga sudah di laksanakan oleh PT. Mancaraya Agro mandiri namun belum di sahkan oleh pemerintah pusat mengingat kondisi areal perusahan berada di hak ulayat masyarakat adat setempat sehingga walaupun belum disahkan namun pihak perusahaan sudah menjalankannya sesuai dengan 
SK. Dirjen PH No. 288/Kpts/IVPHH/1992.

\section{Tahap Pelaksanaan}

Tahap kegiatan pelaksanaan pembinaan terhadap masyarakat di areal IUPHHK PT. Mancaraya Agro Mandiri sesungguhnya sudah dilakukan sejak tahun 2006-2015. Bentuk kegiatannya antara lain membantu dalam pengadaan sarana dan prasarana umum, pelibatan dalam pembangunan fasilitas oprasional di Base Camp Selewok dan perekrutan tenaga kerja masyarakat lokal dalam Kegiatan pengusahaan hutan. Jenisjenis Kegiatan PMDH di IUPHHK PT. Mancaraya Agro Mandiri sampai saat ini mencakup aspek pendidikan, aspek kesehatan, aspek sosial budaya, dan aspek pertanian menetap. Setiap aspek tersebut terdiri dari beberapa kegiatan, misalnya untuk aspek pendidikan terdiri dari kegiatan pemberian bantuan guru honor dan pemberian akomodasi berupa buku terhadap siswa-siswi SD dan SMP yang membutuhkan. Salah satu bentuk kepedulian perushan untuk meningkatkan mutu pendidikan di desa binaannya adalah dengan pengadaan guru honor. Pengadaan guru honor dilakukan oleh perusahan sendiri mulai dari pemberian gaji dan pengawasan langsung kesekolahsekolah.

Selain pemberian bantuan berupa honor kepada guru, PT. Mancaraya Agro Mandiri juga memberikan bantuan akomodasi berupa buku pelajaran kepada sisawasiswi SD dan SMP yang membutuhkan. Pemberian buku pelajaran tersebut disesuaikan dengan permintaan sekolah. Banyak buku yang diberikan kesekolah, namun apabila dana perusahan kurang mencukupi maka buku yang diberikan disesuaikan dengan kesanggupan dana perusahan. Kegiatan PMDH PT. Mancaraya Agro Mandiri pada aspek kesehatan berupa posyandu dan pengobatan gratis. Pengobatan gratis diberikan kepada masyarakat yang dianggap kurang mampu.

\section{Partisipasi Masyarakat Terhadap Kegiatan PMDH}

\section{Partisipasi Masyarakat} Terhadap Perencanaan Kegiatan PMDH

Keterlibatan atau partisipasi masyarakat dalam penyusunan rencana PMDH sangatlah di perlukan. Hal ini dimaksudkan agar kegiatan selaras dengan kebutuhan masyarakat. Keterlibatan masyarakat ini dapat ditunjukan dari tingkat partisipasi pada tahapan perencanaan yang dilakukan. Indikator yang digunakan antara lain seberapa besar peranan pimpinan informal (kepala adat, toko masyarakat), aparat pemerintah lokal, dan kelompok tani dalam proses penyusunan rencana PMDH.

Dalam proses penyusunan rencana tersebut, aparat Kampung Selewok dan Kampung Saengkeduk dan tokoh masyarakatlah yang memegang peranan dalam penentuan jenis bantuan serta penetapan prioritasbantuan. Sedangkan, kelompok masyarakat hanya ikut dalam proses penyepakatanhasil (tidak berpartisipasi aktif).

\section{Partisipasi Masyarakat Pada Tahap Pelaksanaan PMDH}

Tingkat partisipasi masyarakat dalam tahap program pelaksanaan kegiatan PMDH dilihat dari keikutsertaan masyarakat dalam kegiatan penyuluhan dan pembinaan teknis yang diselenggarakan oleh PMDH. Bantuan kesehatan/posyandu, 
serta bantuan keagamaan dan lainlain, sehingga partisipasi masyarakat dalam tahap pelaksanaan PMDH tidak bisa dinilai karena masyarakat hanya menerima bantuan yang diberikan oleh perusahaan.

Adapun beberapa pelaksanaan kegiatan Pembinaan masyarakat desa Hutan oleh IUPHHK PT. Mancara Agro Mandiri yang sudah terlaksana pada 2 kampung binaan oleh IUPHHK PT. Mancara Agro Mandiri yaitu kampung selewok dan Kampung saengkeduk dimana 2 kampung ini menjadi sampel buat peneliti mengambil data dan sampel wawancara oleh masyarakat setempat dan pihak perusahaan.

Pelaksanaan Kegiatan PMDH di Kampung Selewok dan Kampung Saengkeduk berdasarkan wawancara stuktural dan wawancara bebas Masyarakat tokoh adat, masyarakat adat dan pihak perusahan dalam hal ini karyawan perusahan dapat di lihat tahapan di bawah ini :

\section{a. Pembinaan Pertanian Menetap}

b. Peningkatan

EkonomiMasyarakat

Tabel6 Responden Desa Binaan Dalam Segi Manfaat Dan Tidak Bermanfaat

\begin{tabular}{|l|ll|ll|ll|}
\hline $\begin{array}{l}\text { Responden } \\
\text { Desa Binaan }\end{array}$ & \multicolumn{2}{|l|}{ Tdk Bermanfaat } & Bermanfaat & \multicolumn{2}{l|}{$\begin{array}{l}\text { Sangat } \\
\text { Bermanfaat }\end{array}$} \\
\cline { 2 - 7 } & Responden & $\%$ & Responden & $\%$ & Responden & $\%$ \\
\hline Selewok & 2 & 3,33 & 25 & 41.67 & 3 & 5 \\
Saengkeduk & 4 & 6,66 & 23 & 38.33 & 3 & 5 \\
\hline Total & 6 & 10,00 & 48 & 80,00 & 6 & 10 \\
\hline
\end{tabular}

Sumber : Hasil analisis

Dari Tabel diatas dapat dilihat bahwa pada umumnya $(80 \%)$ responden menyatakan bahwa kegiatan PMDH bermanfaat bagi mereka. Adapun alasan responden menyatkan bahwa PMDH bermanfaat karena:

1. Masyarakat petani bisa mendapatkan pupuk, bibit dan bantuan alat pertanian.

2. Tersedianya lahan dan bibit pohon sengon, merbau, matoa

\section{c. Pengembangan Sarana dan Prasarana Umum \\ d. Pengembangan Sosial Budaya \\ e. Konservasi Sumberdaya Hutan dan Lingkungan}

\section{E. Persepsi Masyarakat Terhadap Kegiatan PMDH}

Persepsi responden terhadap manfaat kegiatan PMDH dilihat dari pendapat masyarakat tentang kegiatan PMDH yang berjalan selama ini apakah bermanfaat atau tidak, apakah kegiatan IUPHHK-HA PT. Mancaraya Agro Mandiri bermanfaat bagi masyarakat, dan dengan adanya kegiatan PMDH apakah kebutuhan masyarakat akan hasil hutan terpenuhi. Dari hasil wawancara tersebut diperoleh bahwa sebagian besar responden menyatakan adanya manfaat dari kegiatan PMDH. Persepsi masyarakat terhadap manfaat kegiatan PMDH dapat dilihat pada Tabel dibawah ini 
Sedangkan alasan responden yang menyatakan bahwa kegiatan PMDH tidak bermanfaat sebesar $10 \%$ adalah karena kegiatan PMDH belum berjalan dengan baik, tidak ada pengaruh terhadap kehidupan sehari-hari, tidak ada bantuan personal, dan ada juga karena alasan ketidaktahuan tentang kegiatan PMDH.

Tabel7: Persepsi Masyarakat Terhadap Manfaat Kegiatan PMDH oleh IUPHHK PT. Mancaraya Agro Mandiri

\begin{tabular}{|l|l|l|l|l|l|c|}
\hline \multirow{2}{*}{ Responden Desa } & \multicolumn{2}{l|}{ Tdk Bermanfaat } & \multicolumn{2}{l|}{ Bermanfaat } & \multicolumn{2}{l|}{ Sangat Bermanfaat } \\
\cline { 2 - 7 } & Responden & $\%$ & Responden & $\%$ & Responden & $\%$ \\
\hline Selewok & 4 & 6.66 & 22 & 36.67 & 4 & 6.66 \\
Saengkeduk & 4 & 6.66 & 25 & 41.67 & 1 & 1.66 \\
\hline Total & $\mathbf{8}$ & $\mathbf{1 3 , 3 3}$ & $\mathbf{4 7}$ & $\mathbf{7 8 , 3 3}$ & $\mathbf{5}$ & $\mathbf{8 , 3 3}$ \\
\hline
\end{tabular}

Sumber : Hasil analisis

Tabel diatas memperlihatkan bahwa sebagian besar $(78,33)$ responden menyatakan bahwa kegiatan perusahaan bermanfaat bagi masyarakat dengan alasan berikut : Perusahan menyediakan lapangan kerja kepada masyarakat lokal, perusahan memberikan bantuan apabila masyarakat menghadapi musibah (kebakaran, meninggal Dunia, banjir dan lain-lain), perusahan juga memberikan bantuan keagamaan dan bantuan pembangunan jalan, menyediakan tenaga pengajar dalam rangka meningkatkan pendidikan dan sebagainya. Responden yang menyatakan bahwa kegiatan IUPHHK PT. Mancaraya Agro Mandiri tidak Tabel 8 : Persepsi Masyarakat Terhadap Pemenuhan Mereka Akan Hasil Hutan di PT. Mancaraya Agro Mandiri

\begin{tabular}{|l|l|l|l|l|}
\hline \multirow{2}{*}{ Responden Desa } & \multicolumn{4}{|c|}{ Terpenuhi } \\
\cline { 2 - 5 } Binaan & Responden & $\%$ & Responden & $\%$ \\
\hline Selewok & 17 & 28.33 & 13 & 21.67 \\
Saengkeduk & 15 & 25.00 & 15 & 25.00 \\
\hline Total & $\mathbf{3 2}$ & $\mathbf{5 3 , 3 3}$ & $\mathbf{2 8}$ & $\mathbf{4 6 , 6 7}$ \\
\hline
\end{tabular}

Sumber : Hasil analisis

Dari Tabel 8 dapat dilihat bahwa $53,33 \%$ dari total responden menyatakan bahwa kebutuhan mereka bermanfaat adalah sebesar $(13,33 \%)$ dengan alasan karena tidak pernah terlibat sama sekali dalam kegiatan PMDH. Dari penjelasan diatas dapat dikatakan bahwa secara umum kegiatan PT. Mancaraya Agro Mandiri bermanfaat bagi masyarakat peserta PMDH.

Perlu juga diketahui bagaimanan pendapat masyarakat, apakah setelah adanya kegiatan PMDH dari PT. Mancaraya Agro Mandiri kebutuhan mereka terhadap hasil hutan terpenuhi atau tidak terpenuhi. Persepsi masyarakat terhadap pemenuhan kebutuhan mereka akan hasil hutan dapat dilihat pada Tabel 8.
Persepsi masyarakat terhadap manfaat kegiatan PMDH juga dilihat dari apa pendapat responden tentang manfaat kegiatan IUPHHK-HA PT. Mancaraya Agro Mandiri bagi mereka. Persepsi masyarakat terhadap kegiatan IUPHHK-HA PT. Mancaraya Agro Mandiri dapat dilihat pada Tabel dibawah ini 
menyatakan bahwa kebutuhan mereka akan hasil hutan tidak terpenuhi. Sedangkan alasan dinyatakan kebutuhan akan hasil hutan masih terpenuhi adalah karena masyarakat masih tetap diperkenankan mengambil kayu bakar, rotan, kayu kecil untuk membangun rumah, bisa berburu terkecuali di lokasi koridor satwa. Alasan yang menyatakan bahwa kebutuhan akan hasil hutan tidak terpenuhi adalah tidak adanya keinginan untuk mengambil hasil hutan disebabkan jarak yang jauh, dan umur yang sdh tua sehingga sanggup lagi mengambil hasil hutan. Oleh karena itu bisa dikatakan bahwa adanya kegiatan PMDH tidak mempengaruhi masyarakat untuk mengambil hasil htuan, masyarakat tetap diberi kebebasan untuk mengambil hasil hutan kayu (kayu bakar, rotan, kayu kecil untuk membangun rumah, dan sebagainya) kecuali kayu produksi atau kayu yang besar.

Berdasarkan penjelasan diatas maka persepsi masyarakat terhadap manfaat kegiatan PMDH dapat ditentukan dengan menjumlahkan skor dari ketiga pertanyaan (pendapat responden tentang manfaat kegiatan PMDH dan manfaat kegiatan IUPHHK-HA bagi mereka serta pendapat masyarakat tentang bagaimana pemenuhan kebutuhan mereka akan hasil hutan). Kriteria pengukuran persepsi masyarakat terhadap manfaat kegiatan PMDH.

\section{KESIMPULAN}

\section{A. Kesimpulan}

Dari hasil dan pembahasan penelitian ini dapat disimpulkan bahwa:

1. Kegiatan pembinaan terhadap masyarakat kampung di areal IUPHHK PT. Mancaraya Agro
Mandiri sesungguhnya sudah dilakukan sejak tahun 20062016selama 10 tahun berjalan. Dan sudah memiliki 9 Desa/kampung binaanya itu, namun dalam penelitian ini peneliti mengambil 2 kampung sampel penelitian yang dijadikan acuan kegiatan-kegiatan PMDH oleh IUPHHK PT. Mancara Agro Mandiri yaitu Kampung Selewok dan Kampung Saengkeduk dengan alasan bahwa kedua kampung tersebut sangat dekat dengan base camp perusahan dalam aktifitas produksi hutan kayu.

2. Persepsimasyarakatrespondenpembi naanmasyarakat kampung hutan PT. Mancaraya Agro

Mandiridalamsegimanfaatterdapat (80\%) menyatakanbermanfaat

\section{B. Saran}

Adapun

saran-saran

dalamPenelitian ini antara lain:

1. Mengingat Kegiatan PMDH sudah dilakukan selama 10 tahun berjalan danmemiliki 9 kampung binaan maka saran kami perlu ada penelitian lanjutan mengenai beberapa kampung yang belum terjangkau oleh penelitian.

2. Perluadanya upaya peningkatan kondisi

socialdanekonomimasyarakatsekitar sehinggaaksesuntukmemanfaatkans umberdayaalamdisekitarkawasansec araberlebihandapat di kurangi dengan melihat tingginya manfaat kegiatan PMDH oleh PT. Mancaraya Agro Mandiri sehingga mengambil hasil hutan semakin berkurang.

3. Perludiupayakanadanyabentukpenyu luhanterpadu yang melibatkanpemerintahdaerahuntukm emberikanpemahaman yang tepatmengenaifungsidanperanandari hutan produksi yang dilakukan oleh PT. Mancaraya Agro Mandiri, 
efekkerusakan, pemanfaatan yang berlebihandanpenebangan liar padamasyarakatsekitar dalam kawasan hutan produksi PT. Mancaraya Agro Mandiri.

\section{DAFTAR PUSTAKA}

Abdulbari.1993. Hak Pengusahaan Hutan Mengusahakan Hutan dan Membina Desa.Pusat Pendidikan dan Latihan Kehutanan. Bogor.

Azis NA. 2006. Partisipasi Masyarakat Dalam Program Gerakan Nasional Rehabilitasi Hutan dan Lahan (GN- RHL): Kasus di desa Senagalih dan Pamalayan, Kecamatan Boyong bong serta desa Margaluyu dan Ciburial, Kecamatan Leles, Kabupaten Garut [Skripsi]. Bogor: Fakultas Kehutanan. Institut Pertanian Bogor.

Komisi AMDAL 2011. Analisa Dampak Lingkungan, Komisi AMDAL Kab. Sorong, No.660.1/05/KA/2001 tanggal 11 Oktober 2011

Badan Pusat Statistik (BPS). 2014 Kabupaten Sorong Dalam Angka.

David FR. 2004. Strategic Management. Salemba Empat. Jakarta. Departemen Kehutanan. 2000. Pedoman Praktis Pengelolaan Kegiatan Pembinaan Hutan Bersama Masyarakat Desa Hutan. Jakarta.

Direktorat Jenderal Pengusahaan Hutan. 1992. Surat Keputusan Direktorat Jenderal Pengusahaan Hutan No. 288/Kpts/II$\mathrm{PHH} / 1992$, Tentang Penilaian Keberhasilan HPH Bina Desa Hutan. Jakarta.. 1995. Surat Keputusan Menteri Kehutanan Nomor 69/Kpts/II/1995 tentang Kewajiban Pemegang Hak Pengusahaan Hutan dan
Kewajiban Pemegang Hak Pengusahaan Hutan Tanaman Industri dalam Pembinaan Masyarakat Desa Hutan.

Gohong G. 1993. Tingkat Pendapatan dan Tingkat Kesejahteraan Serta Faktorfaktor yang Mempengaruhinya Pada Daerah Opsusu Sunpei Karuhei di Kabupaten Kapuas Provinsi Kalimantan Tengah [Tesis]. Bogor: Program Pasca Sarjana. Institut Pertanian Bogor.

Insusanty E. 2003. Persepsi, Sikap dan Perilaku Masyarakat Sekitar Hutan Terhadap Nilai Sumber Daya Hutan: Studi kasus di desa Cihanyawar Kecamatan Nagrak Kabupaten Sukabumi [skripsi]. Bogor: Fakultas Kehutanan. Institut Pertanian Bogor

Mosher AT. 1987. Menggerakkan dan Membangun Pertanian. Syaratsyarat Pokok Pembangunan dan Modernisasi. CV.Yasaguna. Jakarta.

Muzakir Y. 2006. Partisipasi Masyarakat dan Tingkat Keberhasilan Tanaman Pada Program Pengelolaan Sumber Daya Hutan Bersama Masyarakat: Kasus di Desa Karang Tengah RPH Babakan Madang BKPH Bogor KPH Bogor Perum Perhutani Unit III Jawa Barat [skripsi]. Bogor: FakultasKehutanan. Institut pertanian Bogor.

Putra AS. 2006. Program Pembinaan Masyarakat Desa Hutan (PMDH) pada PT.Andalas Merapi Timber, Propinsi Sumatera Barat [Skripsi]. Bogor: Fakultas Kehutanan. Institut Pertanian Bogor.

Pujo. 1997. Upaya Pengembangan Pembinaan Masyarakat Desa Hutan $(\mathrm{PMDH})$ pada PT. Kiani 
Lestari, Kabupaten Kutai, Propinsi Kalimantan Timur [skripsi]. Bogor: Fakultas Kehutanan. Institut Pertanian Bogor.

Rangkuti F. 2000. Analisis SWOT Teknik Membedah Kasus Bisnis.Gramedia, Jakarta.

Sardjono MA, Raharjo D, Djauhari A, Mugnidin E, Marbiyanto E, Sudiono E, Butar-butar T, Beukeboom H. 2000. Pembinaan Masyarakat Desa Hutan " Pengantar dan Prinsip Dasar Pengelolaan PMDH". SFMPDephut- GTZ. Jakarta.
Soehardjo A dan Patong D. 1973.SendiSendi Pokok Usahatani. Departemen Ilmu-ilmu Sosial Ekonomi. Fakultas Pertanian. Institut Pertanian Bogor.

Soehoed WP. 1992. Kebijaksanaan Pemerintah dalam Pembangunan Pedesaan.Makalah Semiloka Nasional Pembangunan Masyarakat yangBerkesinambungan.28-29 Juli 1992.Departemen Sosial RI. Jakarta.

Soetrisno L. 1990. Struktur Sosial dan Nilai Budaya dalam Industrialisasi. PS.PLP-IPB. Bogor. 
ISSN 1979-7540 